\title{
Association of GST Genetic Polymorphisms with the Susceptibility to Hepatocellular Carcinoma (HCC) in Chinese Population Evaluated by an Updated Systematic Meta-Analysis
}

\author{
Kui Liu', Lu Zhang ${ }^{2}$, Xialu Lin ${ }^{1}$, Liangliang Chen ${ }^{3}$, Hongbo Shi ${ }^{1}$, Ruth Magaye ${ }^{1}$, Baobo Zou ${ }^{1}$, \\ Jinshun Zhao ${ }^{1 *}$
}

1 Department of Preventative Medicine and Zhejiang Provincial Key Laboratory of Pathological and Physiological Technology, School of Medicine, Ningbo University, Ningbo, Zhejiang Province, People's Republic of China, 2 School of Health Management, Anhui Medical University, Hefei, Anhui Province, People's Republic of China, 3 Yinzhou Peoples' Hospital, Ningbo University, Ningbo, Zhejiang Province, People's Republic of China

\begin{abstract}
Background: Due to the possible involvement of Glutathione S-transferase Mu-1 (GSTM1) and Glutathione S-transferase theta-1 (GSTT1) in the detoxification of environmental carcinogens, environmental toxins, and oxidative stress products, genetic polymorphisms of these two genes may play important roles in the susceptibility of human being to hepatocellular carcinoma. However, the existing research results are not conclusive.

Methods: A systematic literature search using databases (PubMed, Scopus, Embase, Chinese Biomedical Database, Chinese National Knowledge Infrastructure, Wanfang Data, etc.) for the eligible studies meeting the inclusion criteria including casecontrol studies or cohort studies is evaluated using an updated systematic meta-analysis.

Results: Significant increase in the risk of HCC in the Chinese population is found in GSTM1 null genotype $(\mathrm{OR}=1.47,95 \% \mathrm{Cl}$ : 1.21 to $1.79, P<0.001)$ and $G S T T 1$ null genotype $(\mathrm{OR}=1.38,95 \% \mathrm{Cl}: 1.14$ to $1.65, P<0.001)$. Analysis using the random-effects model found an increased risk of HCC in GSTM1-GST1 dual null population (OR $=1.79,95 \% \mathrm{Cl}$ : 1.26 to $2.53, P<0.001)$. In addition, subgroup analyses showed a significant increase in the association of GST genetic polymorphisms (GSTM1, GSTT1, and GSTM1-GSTT1) with HCC in southeast and central China mainland. However, available data collected by this study fail to show an association between GST genetic polymorphisms and HCC in people from the Taiwan region (for GSTM1: OR $=0.78$, $95 \% \mathrm{Cl}: 0.60$ to $1.01, P=0.06$; for GSTT1: OR $=0.94,95 \% \mathrm{Cl}: 0.78$ to $1.14, P=0.546$; for GSTM1-GSTT1: OR $=1.04,95 \% \mathrm{Cl}: 0.81$ to $1.32, P=0.77)$. Sensitivity analysis and publication bias diagnostics confirmed the reliability and stability of this metaanalysis.

Conclusions: Our results indicate that both GSTM1 and GSTT1 null genotypes are associated with an increased HCC risk in Chinese population. Peoples with dual null genotypes of GSTM1-GSTT1 are more susceptible to developing HCC. In conclusion, GST genetic polymorphisms play vital roles in the development of HCC in the Chinese population.
\end{abstract}

Citation: Liu K, Zhang L, Lin X, Chen L, Shi H, et al. (2013) Association of GST Genetic Polymorphisms with the Susceptibility to Hepatocellular Carcinoma (HCC) in Chinese Population Evaluated by an Updated Systematic Meta-Analysis. PLoS ONE 8(2): e57043. doi:10.1371/journal.pone.0057043

Editor: William B. Coleman, University of North Carolina School of Medicine, United States of America

Received November 23, 2012; Accepted January 16, 2013; Published February 20, 2013

Copyright: $\odot 2013$ Liu et al. This is an open-access article distributed under the terms of the Creative Commons Attribution License, which permits unrestricted use, distribution, and reproduction in any medium, provided the original author and source are credited.

Funding: Funding provided by grant number: the National Nature Science Foundation of China (Grant No. 81273111), the Foundations of Innovative Research Team of Educational Commission of Zhejiang Province (T200907), the Nature Science Foundation of Ningbo city (Grant No. 2012A610185), the Ningbo Scientific Projects (2012C5019 and SZX11073), the Scientific Innovation Team Project of Ningbo (No. 2011B82014), Innovative Research Team of Ningbo (2009B21002). This work was partly supported by K. C. Wong Magna Fund in Ningbo University. The funders had no role in study design, data collection and analysis, decision to publish, or preparation of the manuscript.

Competing Interests: The authors have declared that no competing interests exist.

* E-mail: zhaojinshun@nbu.edu.cn

\section{Introduction}

Due to a high mortality, hepatocellular carcinoma $(\mathrm{HCG})$ is one of the most serious health problems worldwide [1-2], which is consisted of approximately $80 \%$ of all primary tumors of liver [3]. Incidence rates in males and females are listed sixth and ninth as the most common cancers, respectively. Incidence rate of HCC has been increasing for several years while overall cancer incidence rate has been decreasing in recent years [4-5].
Environment and genetic factors are believed to be the pathogenesis of HCC [6-8]. Furthermore, previous studies indicated that racial and ethnic variations in the same geographic location could cause result bias in meta-analysis [9-11]. In Asia, people are at higher risk of developing HCG because of chronic infection with hepatitis B virus (HBV) [12-13]. In Europe, not only hepatitis C virus $(\mathrm{HCV})$ and cirrhosis, but alcohol and tobacco smoking are also clearly able to accelerate HCG development [2]. Due to its 


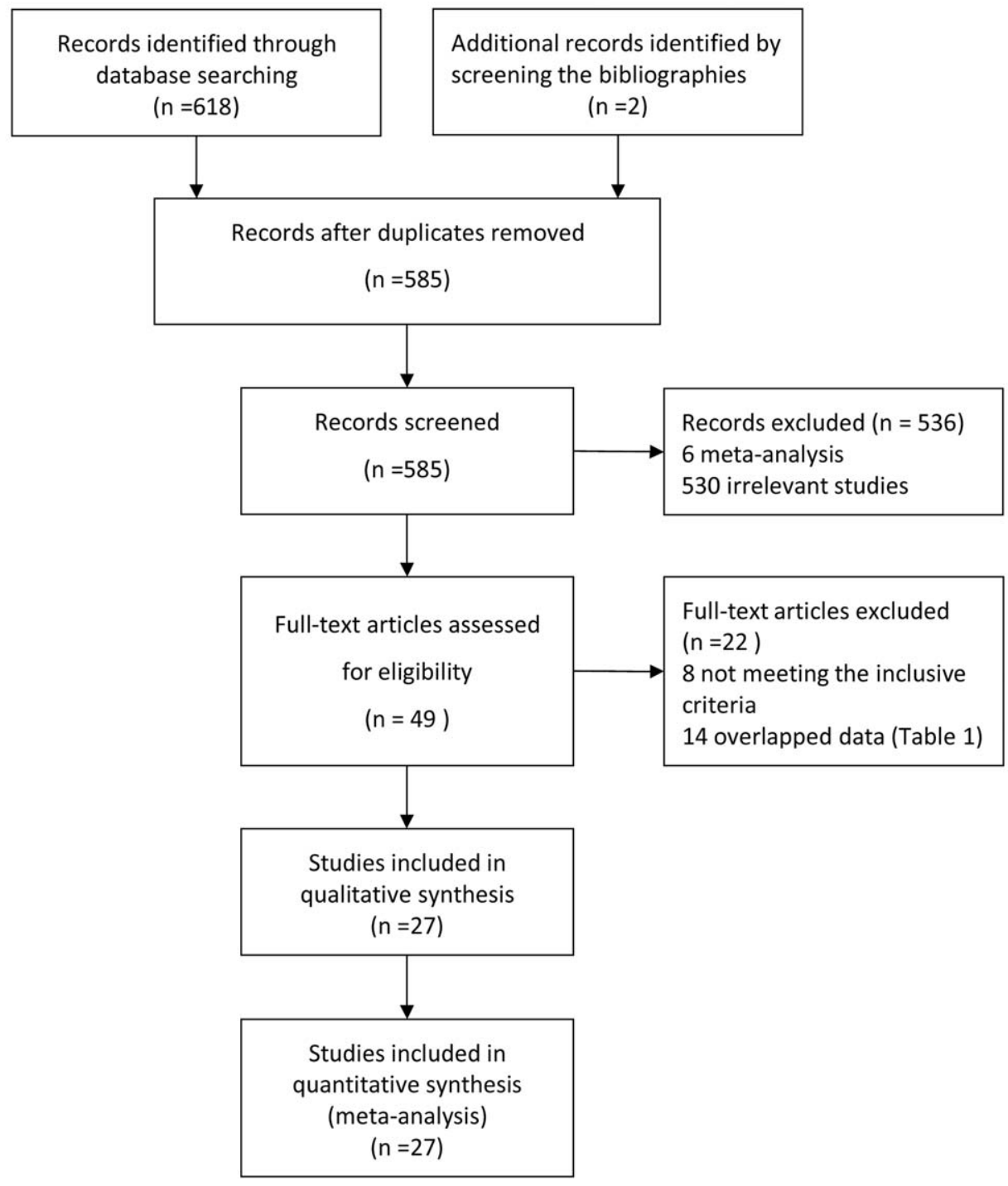

Figure 1. Flow chart of study selection. doi:10.1371/journal.pone.0057043.g001

substantial morbidity and mortality, HCC has been a hot research topic in China in recent years.

The Glutathione $S$-transferases (GSTs) family is an important phase II isoenzyme which can detoxify environmental carcinogens and toxins, oxidative stress products, and modulate the induction of other enzymes and proteins in the cell at the same time [14-16]. Enzymes of GSTs family are composed of many cytosolic, mitochondrial, and MAPEG proteins. Human GSTs can be divided into eight main classes including alpha, mu, pi, theta, sigma, kappa, omega and zeta [17]. GSTM1 and GSTT1 (encoding the $\mathrm{Mu}$ and Theta, respectively) both play important roles in human carcinogenesis. Epidemiologic investigations related to genetic association including case-control and cohort studies suggested the association between GST genetic polymorphisms and HCC risk. However, some of these studies with sparse data, unreasonable and highly underpowered designs, and differential in research methodology could all inevitably influence the robustness of their results. Meta-analysis can avoid these weaknesses by selecting all eligible studies and reducing random error. To identify the association of GST genetic polymorphisms with the susceptibility to hepatocellular carcinoma in the Chinese population, an updated systematic meta-analysis was performed in this study by using a full reference search (from January 1996 to October 2012) and a careful reinvestigation strategy.

\section{Methods}

\section{Literature and Research Strategy}

A computerized literature search was carried out in Embase, PubMed, Scopus, Chinese Biomedical Database (CBM), CochraneLibrary, Chinese National Knowledge Infrastructure (CNKI), and Wanfang Data (the latest research was retrospected to October 2012) to collect articles with case-control or cohort studies related to the association of GSTM1 and/or GSTT1 polymorphisms with the susceptibility of HCC in China. Meanwhile, reference lists of the relevant articles were also collected. Search was performed through websites of http://www. baidu.com and http://scholar.google.cn to identify additional eligible studies. MeSH terms ("glutathione $S$-transferase" or "GST" or "GSTM1" or "GSTT1") and ("hepatocellular carcino- 


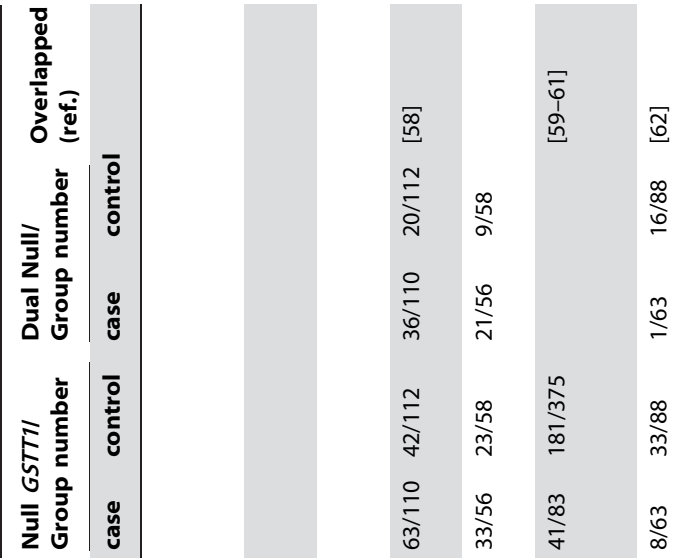

㕆

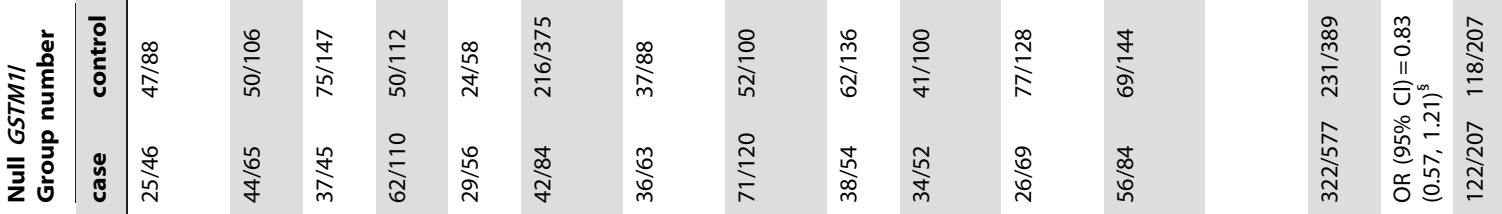

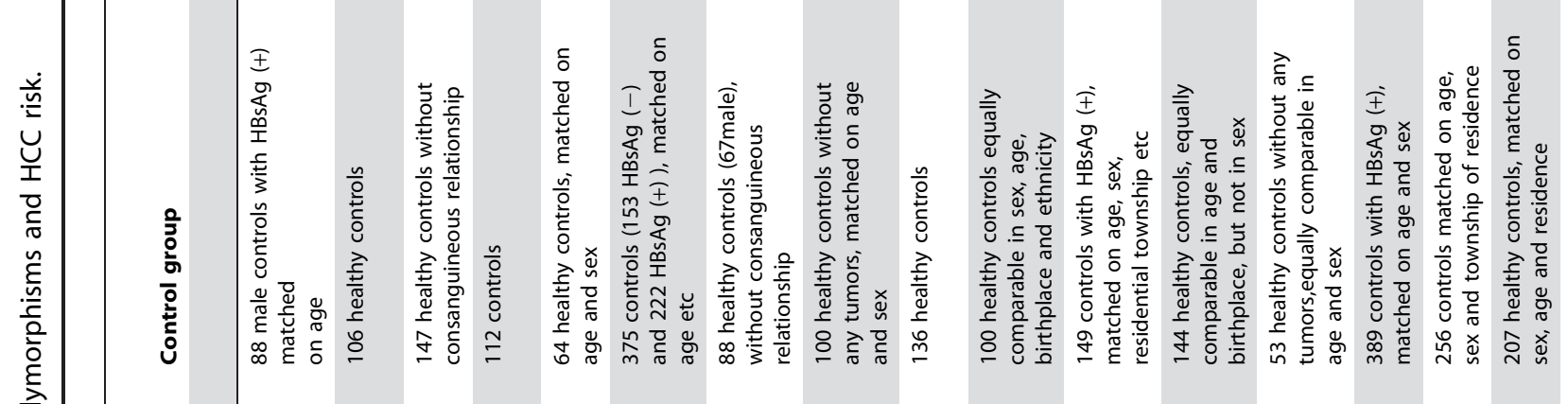

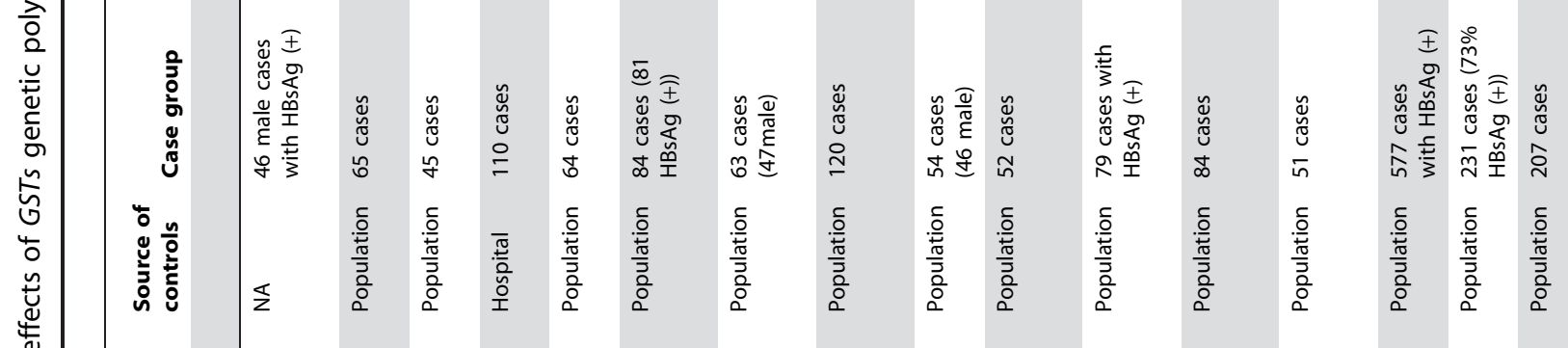

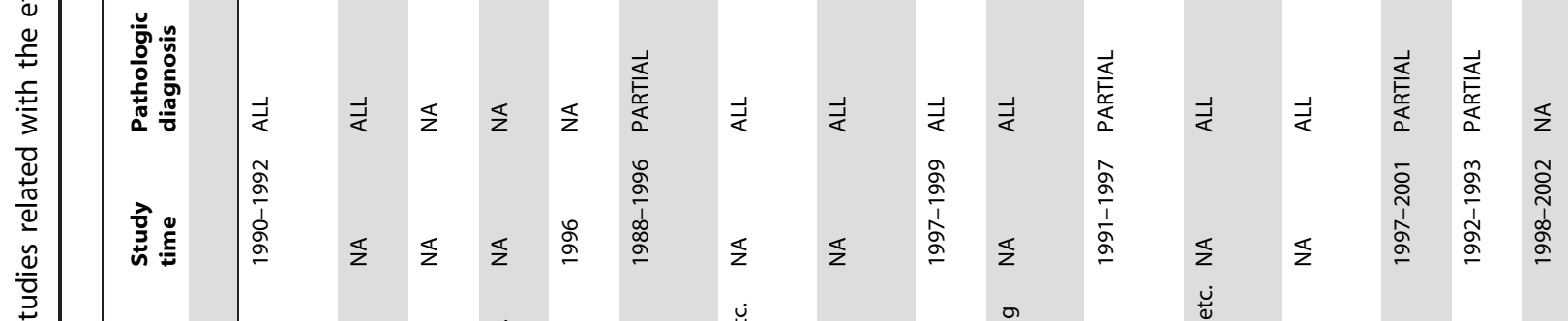

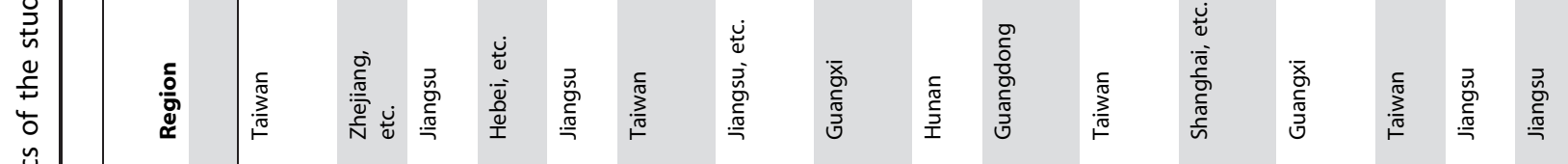

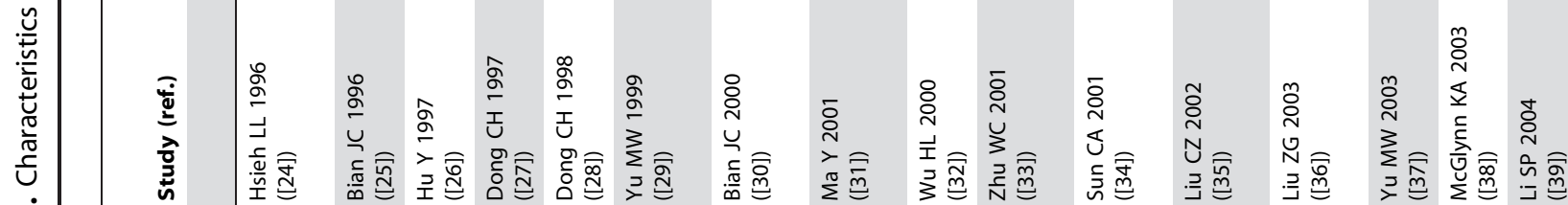

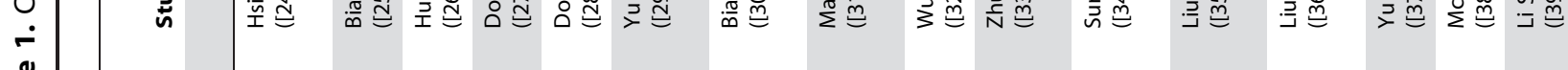

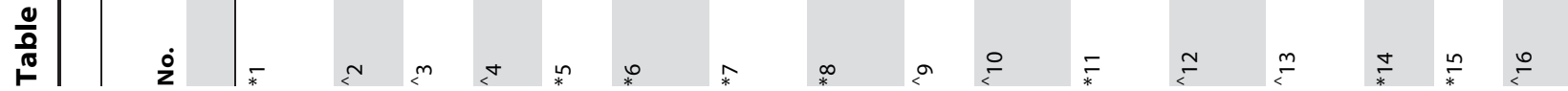




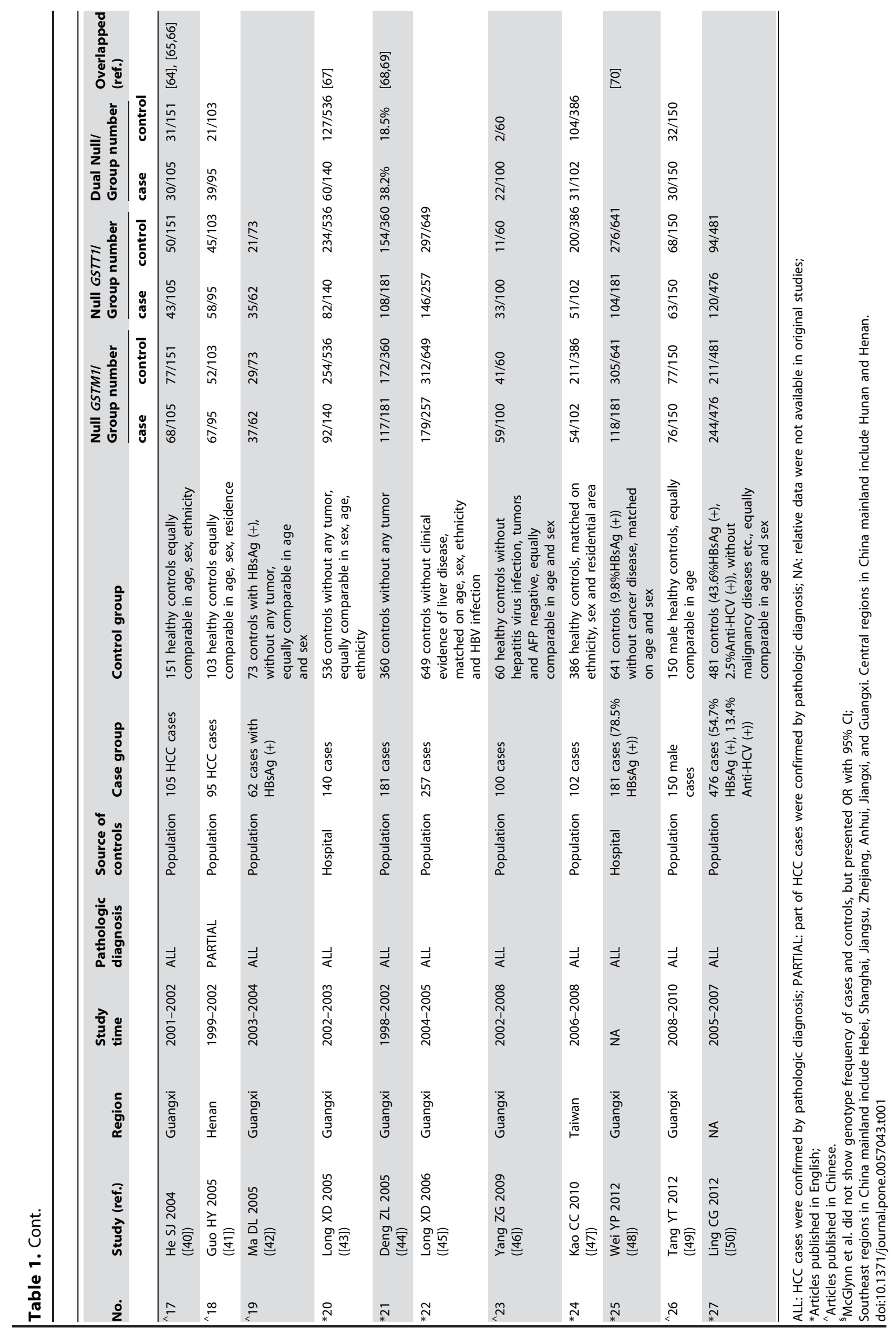




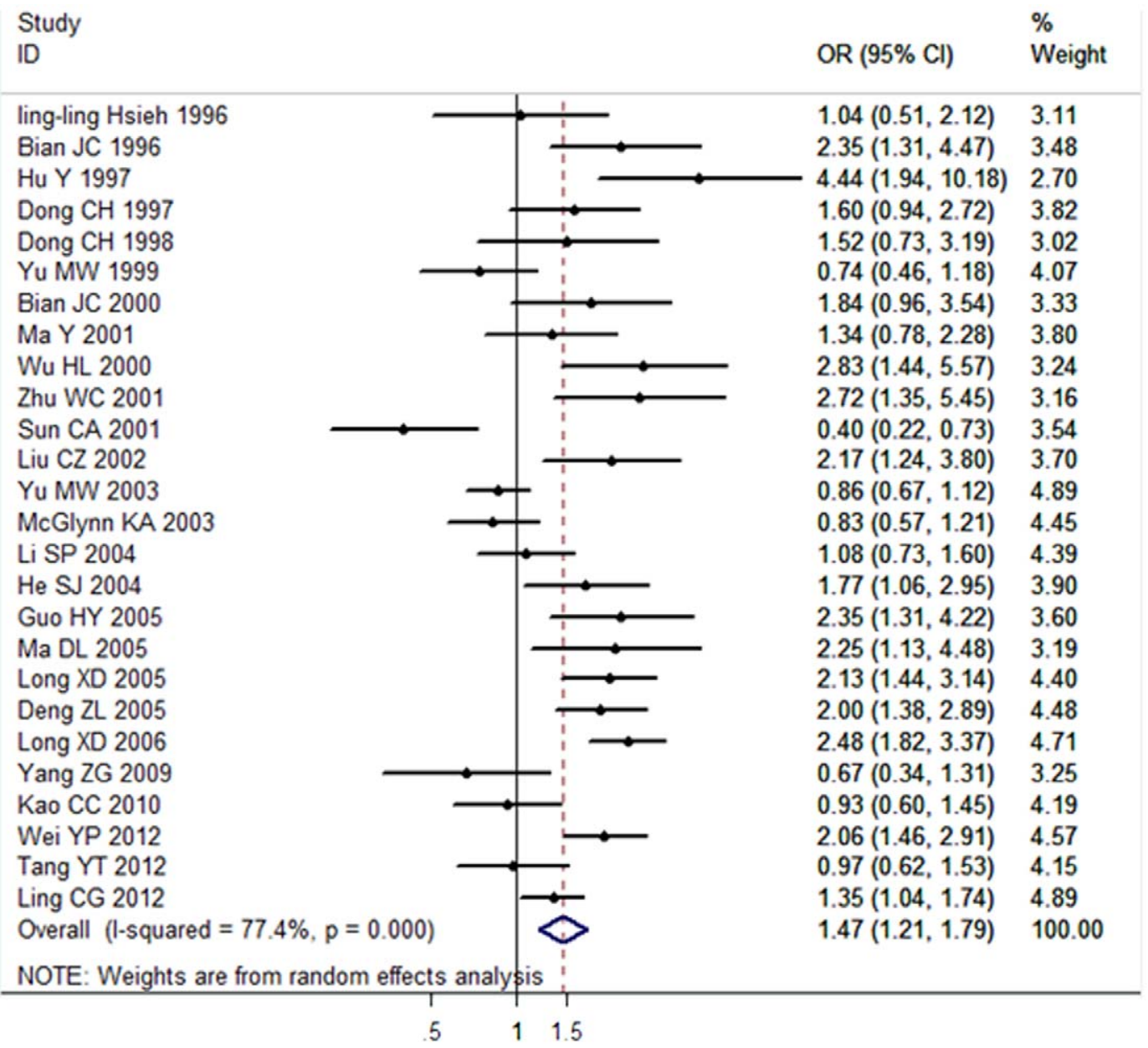

Figure 2. Association between GSTM1 null genotype and HCC risk analyzed by forest plot of meta-analysis. The forest plots of pooled OR with $95 \% \mathrm{Cl}$ (Null genotype vs. Present genotype; $\mathrm{OR}=1.47,95 \% \mathrm{Cl}: 1.21$ to 1.79 ; Random-effects model, $P<0.001$ ). doi:10.1371/journal.pone.0057043.g002

ma" or "liver cancer" or "HCC") and ("China" or "Chinese" or "Taiwan") were used in PubMed. These keyword retrieval strategies were also used in other databases. When there was more than one article published in a same case series, the latest and/or the comprehensive one would be adopted only. Eligible research articles not captured by above research strategies would be further searched by bibliographies.

\section{Inclusion and Exclusion Criteria}

Inclusion criteria are: (1) case-control and cohort studies, in which individuals or samples used for evaluation of the association between GST genetic variances and HCC risk included these owning either with a balance match or not; (2) in the Chinese population; (3) the articles provided raw data including odds ratio (OR) with 95\% confidence interval (CI) and respective variance, or the relevant information could be calculated.

Exclusion criteria are: (1) raw data not available for retrieval; (2) multiple articles based on a same population and published by a same research team, only the latest and/or the largest population study was adopted, others would be excluded; (3) meeting abstract, case reports, editorials, review articles and other meta-analysis were exclusive.

\section{Data Extraction and Synthesis}

To decide inclusively or exclusively, articles were identified by two independent reviewers using a standardized data extraction form designed by our group. Data with discrepancies in identification were discussed. If consensus was not achieved, the decision was made by a third reviewer. Both title and abstract from all potential included articles were screened to identify their relevance. Additionally, if title and abstract were ambiguous, full articles were also investigated. The following information was collected from each study: first author, year of publication, geographical location, study time, pathologic diagnosis, source of control, characteristic of cases and controls, and genotype frequency of null GSTM1, GSTT1 and null of both genotypes in cases and controls.

\section{Statistical Analysis}

(1) The pooled OR and 95\% CI were determined by Z test with $P<0.05$ considered statistically significant; (2) Statistical heterogeneity among studies was assessed with the $Q$ and $\mathrm{I}^{2}$ statistics [18]. The $Q$ test and $\mathrm{I}^{2}$ were claimed to test the variation which was due to heterogeneity or by random error [19]. When $P$ value of heterogeneity tests was no more than $0.1(P \leq 0.1)$, we used random effects model. When $P$ value of heterogeneity test was more than 


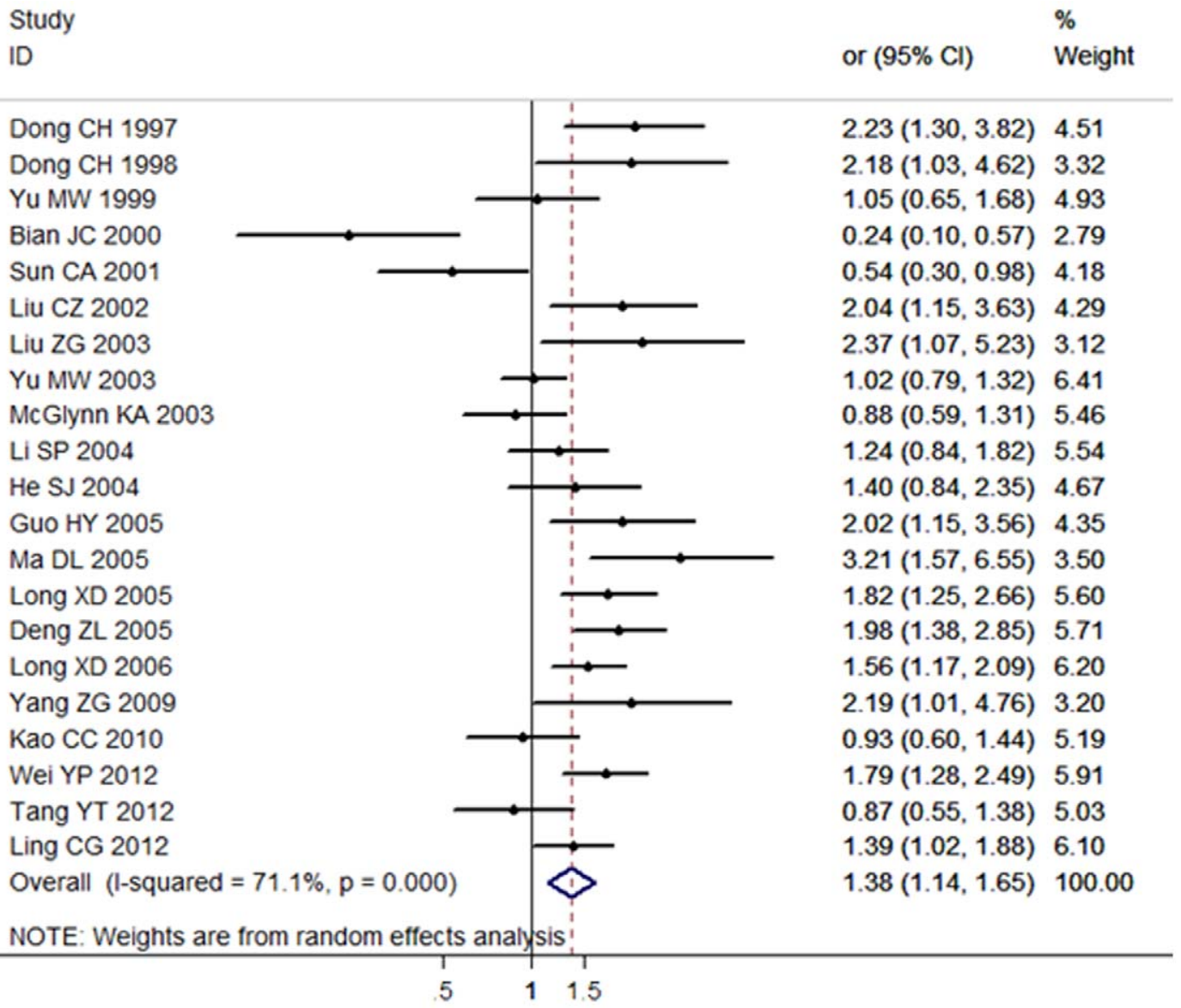

Figure 3. Association between GSTT1 null genotype and HCC risk analyzed by forest plot of meta-analysis. The forest plots of pooled OR with $95 \% \mathrm{Cl}$ (Null genotype vs. Present genotype; OR=1.38, 95\% Cl: 1.14 to 1.65; Random-effects model, $P<0.001$ ). doi:10.1371/journal.pone.0057043.g003

0.1 ( $P>0.1)$, we used fixed effects model [20]; (3) Sensitivity analysis was also tested by removing one study at a time to calculate the overall homogeneity and effect size; (4) Publication bias was investigated with Beggar's funnel plot, in which the standard error of log OR of each study was plotted against its OR [21]; (5) Publication bias was further assessed by the method of Egger's linear regression test which could assess the relationship between effect size and variance differs between large and small studies [22]; (6) In this meta-analysis, subgroup analyses were used to better investigate possible reasons of between-study heterogeneity [23]. The subgroups are as following: geographical location (southeast and central China mainland, and Taiwan region), number of case $(<100$ vs. $\geq 100)$, source of control (populationbased vs. hospital-based); (7) All analyses were performed using the software State version12.0 (StataCorp LP,College Station,Texas,USA), Review Manager 5.0 (Cochrane collaboration, http:// www.cc-ims.net/RevMan/relnotes.htm). All the $P$ values were two sided.

\section{Results}

\section{Study Selection and Study Characteristics}

We ultimately identified a total of 27 articles reporting the relationship between GST genetic polymorphisms and HCC risk by both Chinese and English database [24-50] (Figure 1). According to the inclusive and exclusive criteria, all articles were retrieved and carefully reviewed to assess the eligibility. The characteristics of the studies including 26 articles of GSTM1 (3712 cases and 6024 controls), 21 articles of GSTT1 (3378 cases and 5400 controls) and 12 articles of both GSTM1 and GSTT1 (1562 cases and 2537 controls) are shown in Table 1.

\section{Meta-analysis Results}

2.1. GSTM1 null genotype with HCG risk. 26 articles $[24$ 35, and 37-50] including 3712 cases and 6024 controls were investigated in this study to evaluate the association between GSTM1 null genotype and HCG susceptibility. 12 articles were published in Chinese and 14 articles in English. Results obtained from a random-effects model showed a significant association between the GSTM1 null genotype and HCG risk in the Chinese population $(\mathrm{OR}=1.47,95 \% \mathrm{CI}: 1.21$ to $1.79, P<0.001)$. The forest plot was showed in Figure 2.

2.2. GSTT1 null genotype with HCG risk. 21 articles including 3378 cases and 5400 controls were used for the investigation of the association between GSTT1 null genotype and HCC susceptibility. 9 articles were published in Chinese and 12 articles were published in English. Results showed that the GSTM1 null genotype was significantly associated with HCC risk demonstrated by random-effects model in the Chinese population $(\mathrm{OR}=1.38,95 \% \mathrm{CI}: 1.14$ to $1.65, P<0.001)$. The forest plot was shown in Figure 3. 
Study

ID

or $(95 \% \mathrm{Cl})$

$\%$

Weight

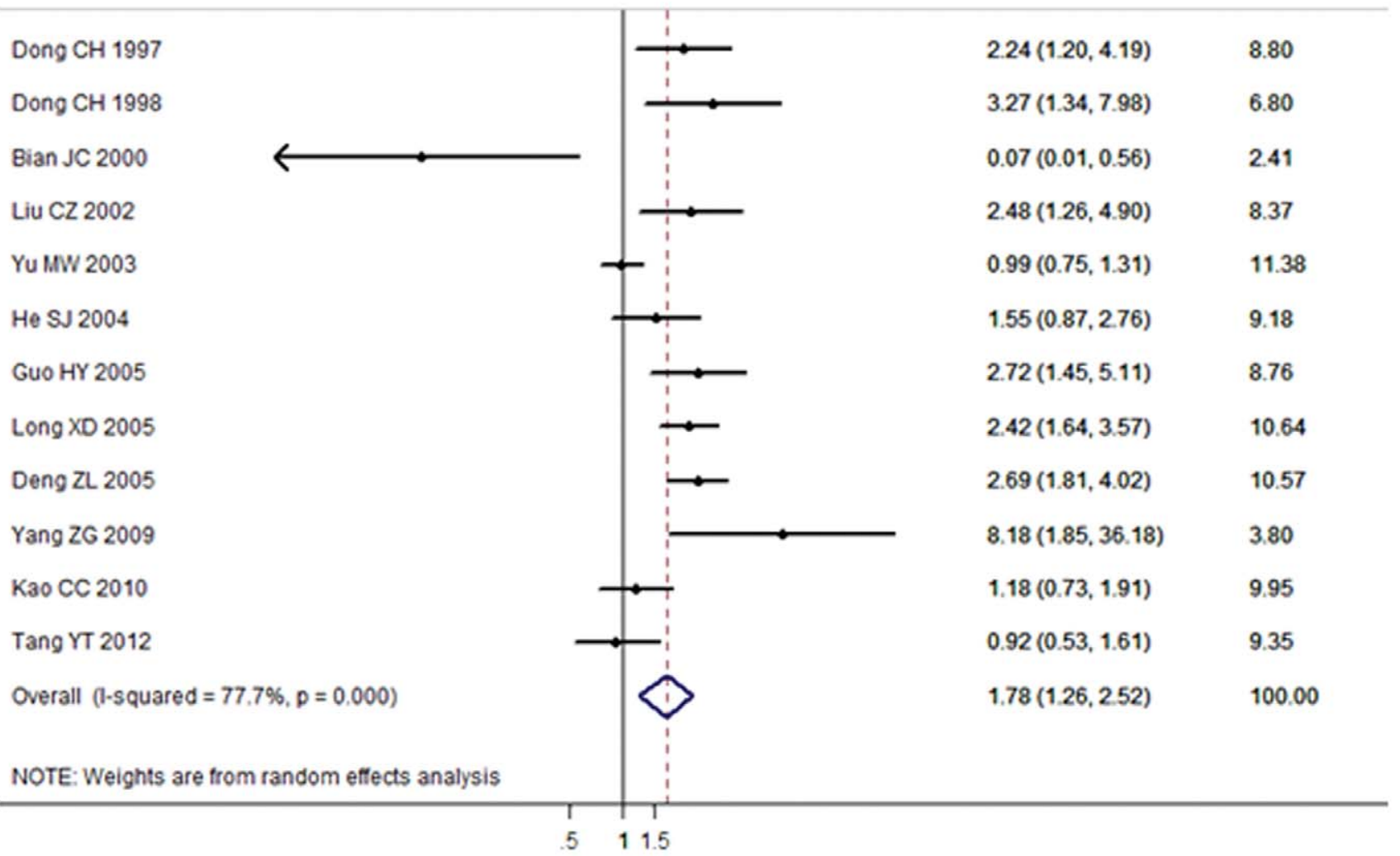

Figure 4. Association between GSTM1-GSTT1 dual-null genotype and HCC risk analyzed by forest plot of meta-analysis. The forest plots of pooled OR with $95 \% \mathrm{Cl}$ (Dual-null genotype vs. Present genotype; OR=1.79, 95\% Cl: 1.26 to 2.53; Random-effects model, $P<0.001$ ). doi:10.1371/journal.pone.0057043.g004

Table 2. Subgroup analysis of the association between GSTM1 null genotype and HCC risk.

\begin{tabular}{|c|c|c|c|c|c|c|c|c|}
\hline \multirow[t]{2}{*}{ Polymorphism } & \multirow{2}{*}{ Null vs. Present } & \multirow[t]{2}{*}{$\begin{array}{l}\text { No. of studies } \\
\text { (cases/controls) }\end{array}$} & \multicolumn{2}{|l|}{ Odds ratio } & \multirow[t]{2}{*}{$\mathbf{M}$} & \multicolumn{2}{|c|}{ Heterogeneity } & \multirow{2}{*}{$P_{E}$} \\
\hline & & & OR [95\% CI] & POR & & $I^{2}(\%)$ & $P H$ & \\
\hline \multirow[t]{11}{*}{ GSTM1 } & All studies & $26(3712 / 6024)$ & $1.47[1.21,1.79]$ & $<0.001$ & $\mathrm{R}$ & $77.4 \%$ & $<0.001$ & 0.367 \\
\hline & subgroup analyses by geographical location & & & & & & & \\
\hline & Southeast regions in mainland China & 18(2209/3938) & $1.69[1.38,2.07]$ & $<0.001$ & $\mathrm{R}$ & $67.0 \%$ & $<0.001$ & 0.805 \\
\hline & Central regions in mainland China & $2(149 / 239)$ & $2.55[1.64,3.97]$ & $<0.001$ & $\mathrm{~F}$ & $0.0 \%$ & 0.680 & @ \\
\hline & Taiwan province & $5(878 / 1366)$ & $0.78[0.60,1.01]$ & 0.06 & $\mathrm{~F}$ & $38.1 \%$ & 0.164 & 0.555 \\
\hline & subgroup analyses by number of case & & & & & & & \\
\hline & $<100$ & $12(775 / 1546)$ & $1.59[1.33,1.90]$ & $<0.001$ & $\mathrm{R}$ & $77.8 \%$ & $<0.001$ & 0.031 \\
\hline & $\geq 100$ & 14(2937/4478) & $1.36[1.23,1.50]$ & $<0.001$ & $\mathrm{R}$ & $78.4 \%$ & $<0.001$ & 0.859 \\
\hline & subgroup analyses by source of control & & & & & & & \\
\hline & population-based & $21(3133 / 4261)$ & $1.47[1.17,1.84]$ & $<0.001$ & $\mathrm{R}$ & $79.4 \%$ & $<0.001$ & 0.238 \\
\hline & hospital-based & $4(533 / 1675)$ & $1.62[1.11,2.37]$ & 0.012 & $\mathrm{R}$ & $69.1 \%$ & 0.021 & 0.472 \\
\hline
\end{tabular}

M: model of meta-analysis; R: random-effects model; F: fixed-effects model. $P_{H}: P$ value of heterogeneity test. $P_{E}: P$ value of Egger's test. $P_{O R}: P<0.001$ replace $P=0.000$ and $P$ less than 0.001. @: $P$ values could not be calculated.

doi:10.1371/journal.pone.0057043.t002 
Table 3. Subgroup analysis of the association between GSTT1 null genotype and HCC risk.

\begin{tabular}{|c|c|c|c|c|c|c|c|c|}
\hline \multirow[t]{2}{*}{ Polymorphism } & \multirow{2}{*}{ Null vs. Present } & \multirow[t]{2}{*}{$\begin{array}{l}\text { No. of studies } \\
\text { (cases/controls) }\end{array}$} & \multicolumn{2}{|l|}{ Odds ratio } & \multirow[t]{2}{*}{$\mathbf{M}$} & \multicolumn{2}{|c|}{ Heterogeneity } & \multirow{2}{*}{$P_{E}$} \\
\hline & & & OR $[95 \% \mathrm{Cl}]$ & POR & & $\mathbf{I}^{2}(\%)$ & $P H$ & \\
\hline \multirow[t]{11}{*}{ GSTT1 } & All studies & $21(3378 / 5400)$ & $1.38[1.14,1.65]$ & $<0.001$ & $\mathrm{R}$ & $71.1 \%$ & $<0.001$ & 0.795 \\
\hline & subgroup analyses by geographical location & & & & & & & \\
\hline & Southeast regions in mainland China & $16(2454 / 4019)$ & $1.51[1.35,1.69]$ & $<0.001$ & $\mathrm{R}$ & $67.1 \%$ & $<0.001$ & 0.952 \\
\hline & Central regions in mainland China & 1(95/103) & $2.02[1.15,3.56]$ & 0.020 & $\mathrm{~F}$ & @ & $@$ & $@$ \\
\hline & Taiwan province & $4(829 / 1278)$ & $0.94[0.78,1.14]$ & 0.546 & $\mathrm{~F}$ & $24.4 \%$ & 0.265 & 0.315 \\
\hline & subgroup analyses by number of case & & & & & & & \\
\hline & $<100$ & $8(561 / 1022)$ & $1.34[0.78,2.28]$ & 0.258 & $\mathrm{R}$ & $81.8 \%$ & $<0.001$ & 0.961 \\
\hline & $\geq 100$ & $13(2817 / 4378)$ & $1.38[1.16,1.64]$ & 0.002 & $\mathrm{R}$ & $61.0 \%$ & $<0.001$ & 0.560 \\
\hline & subgroup analyses by source of control & & & & & & & \\
\hline & population-based & $17(2845 / 3725)$ & $1.32[1.06,1.64]$ & $<0.001$ & $\mathrm{R}$ & $72.1 \%$ & $<0.001$ & 0.746 \\
\hline & hospital-based & $4(533 / 1675)$ & $1.60[1.14,2.26]$ & 0.007 & $\mathrm{R}$ & $63.6 \%$ & 0.041 & 0.929 \\
\hline
\end{tabular}

M: model of meta-analysis; R: random-effects model; $F$ : fixed-effects model. $P_{H}: P$ value of heterogeneity test. $P_{E}: P$ value of Egger's test. $P_{O R}: P<0.001$ replace the $P=0.000$ and the $P$ less than 0.001 . @: $P$ values could not be calculated.

doi:10.1371/journal.pone.0057043.t003

2.3. Dual-null genotype of GSTM1-GSTT1 with HCG risk. 12 articles (6 articles in Chinese and 6 articles in English) including 1763 cases and 2537 controls were used to evaluate the relationship between GSTM1-GSTT1 null genotype and HCC susceptibility. Results indicated that dual-null genotype of GSTM1GSTT1 also had a significant association with HCG risk in the Chinese population $(\mathrm{OR}=1.79,95 \%$ CI: 1.26 to $2.53, P<0.001)$. The forest plot was shown in Figure 4.

\section{Subgroup Analysis}

The substantial between-study heterogeneity of the three above analyses were observed ( $P$ values for GSTM1, GSTT1, and the interaction of GSTM1-GSTT1 were all less than $0.001, \mathrm{I}^{2}$ values were $77.4 \%, 71.1 \%$, and $77.7 \%$, respectively). In this metaanalysis, subgroup analyses contained geographical location (southeast regions in China mainland, central regions in China mainland, and Taiwan region), case number $(<100$ vs. $\geq 100)$, source of control (population-based vs. hospital-based). The between-study heterogeneity showed that the major source of heterogeneity came from China mainland population. Association between GST genetic polymorphisms and HCG risk increase was significant in subgroup analyses of both southeast and central regions in China mainland population, but no significant in Taiwan population. Other subgroup analyses results were shown in Table 2, Table 3, and Table 4.

\section{Sensitivity and Heterogeneity Analysis}

Sensitivity analysis was performed by sequential excluding one article each time. The significance of all ORs was not changed. We used Galbraith plot to omit some possible major sources of heterogeneous articles. The results were showed in Figure 5. In Figure 5A, we found more than 6 articles (No. 3, 6, 11, 13, 14, and

Table 4. Subgroup analysis of the association between GSTM1-GSTT1 null genotype and HCC risk.

\begin{tabular}{|c|c|c|c|c|c|c|c|c|}
\hline \multirow{2}{*}{ Polymorphism } & \multirow[t]{2}{*}{ Null vs. Present } & \multirow[t]{2}{*}{$\begin{array}{l}\text { No. of studies } \\
\text { (cases/controls) }\end{array}$} & \multicolumn{2}{|l|}{ Odds ratio } & \multirow[t]{2}{*}{$\mathbf{M}$} & \multicolumn{2}{|c|}{ Heterogeneity } & \multirow{2}{*}{$P_{E}$} \\
\hline & & & OR [95\% Cl] & POR & & $I^{2}(\%)$ & $P H$ & \\
\hline \multirow[t]{11}{*}{ GSTM1-GSTT1 } & All studies & 12(1763/2537) & $1.78[1.26,2.52]$ & $<0.001$ & $\mathrm{R}$ & $77.7 \%$ & $<0.001$ & 0.535 \\
\hline & subgroup analyses by geographical location & & & & & & & \\
\hline & Southeast regions in mainland China & $9(989 / 1659)$ & $1.98[1.32,2.95]$ & $<0.001$ & $\mathrm{R}$ & $70.3 \%$ & $<0.001$ & 0.497 \\
\hline & Central regions in mainland China & $1(95 / 103)$ & $2.72[1.45,5.11]$ & 0.002 & $\mathrm{~F}$ & @ & @ & @ \\
\hline & Taiwan province & $2(679 / 775)$ & $1.04[0.81,1.32]$ & 0.770 & $\mathrm{~F}$ & $0.0 \%$ & 0.536 & @ \\
\hline & subgroup analyses by number of case & & & & & & & \\
\hline & $<100$ & $4(298 / 393)$ & $1.73[0.70,4.28]$ & 0.235 & $\mathrm{R}$ & $75.9 \%$ & 0.001 & 0.115 \\
\hline & $\geq 100$ & $8(1465 / 2144)$ & $1.70[1.17,2.48]$ & 0.006 & $\mathrm{R}$ & $78.8 \%$ & 0.001 & 0.263 \\
\hline & subgroup analyses by source of control & & & & & & & \\
\hline & population-based & $9(1411 / 1503)$ & $1.75[1.09,2.80]$ & 0.020 & $\mathrm{R}$ & $81.0 \%$ & 0.001 & 0.531 \\
\hline & hospital-based & $3(352 / 1034)$ & $1.86[1.16,2.97]$ & 0.010 & $\mathrm{R}$ & $63.8 \%$ & 0.063 & 0.856 \\
\hline
\end{tabular}

M: model of meta-analysis; R: random-effects model; F: fixed-effects model. $P_{H}: P$ value of heterogeneity test. $P_{E}: P$ value of Egger's test. $P_{O R}: P<0.001$ replace the $P=0.000$ and the $P$ less than 0.001 . @: $P$ values could not be calculated.

doi:10.1371/journal.pone.0057043.t004 

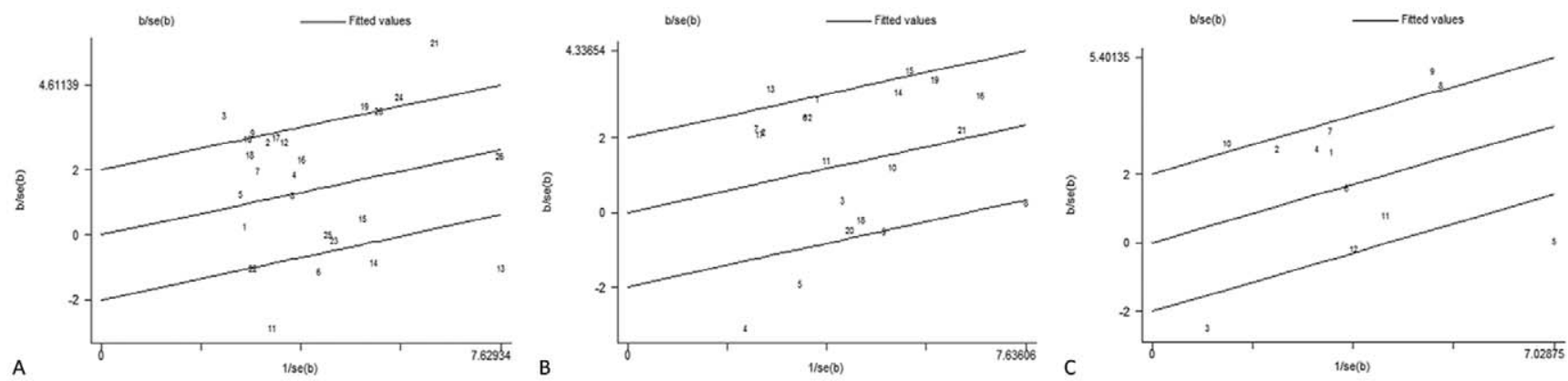

Figure 5. Galbraith plot of association between GST polymorphisms and HCC risk. Each figure represents a unique article in this metaanalysis. The figures outside the three lines are spotted as the outliers and the possible sources of heterogeneity in the analysis pooled of total available studies. (A) Galbraith plot identifies the outliers from 26 studies about GSTM1 polymorphisms and HCC risk. (B) Galbraith plot identifies the outliers from 21 studies about GSTT1 polymorphisms and HCC risk. (C) Galbraith plot identifies the outliers from 12 studies about GSTM1-GSTT1 polymorphisms and HCC risk.

doi:10.1371/journal.pone.0057043.g005

21) spotted by Galbraith plot. However, it might cause some biases by excluding those articles as the sources of heterogeneity. So we didn't reduce the obvious between-study heterogeneity in the analyses on the GSTM1 polymorphisms. In Figure 5B, 3 articles (No. 4, 5 and 13) were obviously spotted as the outliers and the possible sources of heterogeneity in the analysis pooled of total available studies, but another 3 articles (No. 8, 9 and 15) the outliers were not reduced because it could cause some biases. After adjustment, the association between GSTT1 polymorphisms and HCG risk was increased $(\mathrm{OR}=1.45,95 \% \mathrm{CI}: 1.24$ to 1.69 , $P<0.001$, random-effects model). Galbraith plots (Figure $5 \mathrm{C}$ ) spotted 5 articles (No. 3, 5, 8, 9 and 10) as the possible sources of heterogeneity, but only 3 articles (No. 3, 5 and 9) were omitted for the obvious between-study heterogeneity in the analyses on the GSTM1-GSTT1 polymorphisms. The adjusted OR and 95\% CI between GSTM1/GSTM1-GSTT1 polymorphisms and HCG risk was significantly increased although heterogeneity $\left(\mathrm{I}^{2}{ }_{\text {GSTT1 }}=56.1 \%, \quad P_{\text {GSTT1 }}=0.002 ; \quad \mathrm{I}_{\text {GSTM1-GSTT1 }}^{2}=59.0 \%\right.$, $\left.P_{\text {GSTM1-GSTT1 }}=0.012\right)$ still existed. These results were shown in Table 5 and Table 6.

\section{Potential Publication Bias}

Beggar's funnel plots and Egger's publication bias plots were used to assess the potential publication bias for GSTM1, GSTT1, and dual-null genotype of GSTM1-GSTT1 (Figure 6). No publication bias was detected by Egger's test $\left(P_{E}=0.367\right.$ for GSTM1, $P_{E}=0.795$ for GSTT1 and $P_{E}=0.64$ for dual-null genotype of GSTM1-GSTT1).

\section{Discussion}

The association between GST genetic polymorphisms and HCC risk are inconsistent according to the present research results. This may be caused by several reasons. Improper matching or insufficient case and control numbers used in the studies are all possible reasons. One meta-analysis [10] published in 2009 with the association between GST genetic polymorphisms and HCC risk didn't cover all conclusive articles published in Chinese and English databases. In this meta-analysis paper, overlapped data was found in two adopted studies [37,51] (two different articles with different case and control numbers written by the same research group). Another two adopted studies [52,53] in this metaanalysis didn't match properly for the cases (HBV carried) and controls (HBV negative). The other meta-analysis [11] published in 2012 about Asian population included a study [ $\left.{ }^{38}\right]$ with unclear case and control numbers. In addition, some more studies [47-50] related with the association between GST genetic polymorphisms and HCC risk have emerged since these two meta-analysis papers were published.

To evaluate the association of GST genetic polymorphisms and susceptibility to HCG in the Chinese population, we performed an updated systematic meta-analysis. In this study, 27 articles (3781 patients and 6104 controls) were selected from Chinese and English databases. 26 studies (3712 cases and 6024 controls) out of the 27 articles were used for investigation of the relationship between GSTM1 null genotype and HCG susceptibility. 21 studies (3378 cases and 5400 controls) out of the 27 articles were used to evaluate the relationship between GSTT1 null genotype and HCC susceptibility. 12 studies (1763 cases and 2537 controls) were applied for evaluation for the GSTM1-GSTT1 gene. Random-

Table 5. Subgroup analysis of ${ }^{\$}$ the adjusted association between GSTT1 null genotype and HCC risk.

\begin{tabular}{|c|c|c|c|c|c|c|c|c|}
\hline \multirow{2}{*}{ Polymorphism } & \multirow{2}{*}{ Null VS. Present } & \multirow[t]{2}{*}{$\begin{array}{l}\text { No. of studies } \\
\text { (cases/controls) }\end{array}$} & \multicolumn{2}{|l|}{ Odds ratio } & \multirow{2}{*}{$\mathbf{M}$} & \multicolumn{2}{|c|}{ Heterogeneity } & \multirow{2}{*}{$P_{E}$} \\
\hline & & & OR $[95 \% \mathrm{Cl}]$ & POR & & $I^{2}(\%)$ & $P H$ & \\
\hline GSTT1 & All studies & $18(3186 / 5111)$ & $1.45[1.24,1.69]$ & $<0.001$ & $\mathrm{R}$ & $56.1 \%$ & 0.002 & 0.142 \\
\hline
\end{tabular}


Table 6. Subgroup analysis of ${ }^{\$}$ the adjusted association between GSTM1-GSTT1 null genotype and HCC risk.

\begin{tabular}{|c|c|c|c|c|c|c|c|c|}
\hline \multirow{2}{*}{ Polymorphism } & \multirow{2}{*}{ Null vs. Present } & \multirow[t]{2}{*}{$\begin{array}{l}\text { No. of studies } \\
\text { (cases/controls) }\end{array}$} & \multicolumn{2}{|l|}{ Odds ratio } & \multirow[t]{2}{*}{$\mathbf{M}$} & \multicolumn{2}{|c|}{ Heterogeneity } & \multirow{2}{*}{$P_{E}$} \\
\hline & & & OR $[95 \% \mathrm{Cl}]$ & $P O R$ & & $I^{2}(\%)$ & $P H$ & \\
\hline GSTM1-GSTT1 & All studies & $9(942 / 1674)$ & $1.98[1.43,2.74]$ & $<0.001$ & $\mathrm{R}$ & $59.0 \%$ & 0.012 & 0.236 \\
\hline
\end{tabular}

effects model of meta-analysis shows significant associations of polymorphisms of GSTM1 null gene $(\mathrm{OR}=1.47,95 \%$ CI: 1.21 to 1.79, $P<0.001)$, GSTT1 null gene $(\mathrm{OR}=1.38,95 \% \mathrm{CI}: 1.14$ to 1.65, $P<0.001)$, and GSTM1-GSTT1 dual null gene $(\mathrm{OR}=1.79$, 95\% CI: 1.26 to $2.53, P<0.001)$, respectively, with HCG risk in the Chinese population. Subgroup analyses on GSTM1 null gene indicate that geographical location (China mainland, but not in Taiwan region), case numbers and source of controls are significantly associated with HCG risk. Results of subgroup analyses on GSTT1 null gene and GSTM1-GSTT1 dual null gene indicate that geographical location (China mainland, but not in Taiwan region), case numbers $(\geq 100$, but not $<100)$ and source of controls are also significantly associated with HCC risk. Reasons for inconsistent in conclusions between China mainland and Taiwan region may be caused by environmental factors. Moreover, limited investigative numbers of the case-control/ followed up studies from Taiwan region may result in difficulty for getting stable risk estimation, though these investigations own low between-study heterogeneity. In addition, studies with case number less than 100 may have effects on drawing a proper estimation for the association between GST genetic polymorphisms and HCG risk. Therefore, further well design case-control/ followed-up studies, especially with a larger case number, are necessary to provide better evidences for the evaluation. Heterogeneity analysis is a key part of meta-analysis. Q statistic test (Cochran's Q statistic) and $\mathrm{I}^{2}$ statistic test are commonly used to test and quantify the between-study heterogeneity. The major source of heterogeneity in the China mainland population detected in the subgroup analysis might come from the environmental difference which could affect their sensitivity to particular genomic variants. In this meta-analysis, Galbraith plot was performed for identifying the articles with possible heterogeneity. However, in the analyses on the GSTM1 polymorphism and HCC risk, we kept several articles with obvious between-study heterogeneity because too many articles omitting could cause some biases. For the association of GSTT1 null gene and HCC risk, we deleted 3 articles $[30,34,42]$ which were obviously spotted as the outliers with major source of between-heterogeneity, and same procedures were done for GSTM1-GSTT1 gene (3 article deletion $[30,37,44])$. Regretfully, the between-heterogeneity didn't decrease significantly even if the adjustment was done in both GSTT1 and GSTM1-GSTT1 genetic polymorphisms $\left(\mathrm{I}^{2}{ }_{\text {GSTT } 1}=56.1 \%, \quad P_{\text {GSTT } 1}=0.002 ; \quad \mathrm{I}^{2}\right.$ GSTM1-GSTT1 $=59.0 \%$, $P_{\text {GSTM1-GSTT1 }}=0.012$ ). Therefore, we applied the random-effects model to evaluate the pooled OR for GSTT1 and GSTM1-GSTT1 genes, respectively. After the above adjustments, the associations were increased between GSTT1 and GSTM1-GSTT1 polymorphisms and HCG risk $\left(\mathrm{OR}_{G S T T 1}=1.45,95 \%\right.$ CI: 1.24 to 1.69 ; $\mathrm{OR}_{\text {GSTM1-GSTT1 }}=1.98,95 \%$ CI: 1.43 to 2.74$)$. In this study, Beggar's funnel plots and Egger's linear regression test were applied to assess the potential publication bias. No publication bias was detected $\left(P_{E}=0.367\right.$ for GSTM1, $P_{E}=0.795$ for GSTT1 and $P_{E}=0.64$ for dual-null genotype of GSTM1-GSTT1, Egger's linear regression test).

Research evidences suggest that GST genetic polymorphisms are associated with the susceptibility to several carcinomas. Takahiko Katoh et al. [54] showed the GSTM1 null genotype might be associated with susceptibility to gastric adenocarcinoma and distal colorectal adenocarcinoma in Japanese population. Wang $\mathrm{J}$ et al. [55] found that the combination of GSTM1 null and GSTP1 Val was significantly associated with an elevated lung adenocarcinoma risk $(\mathrm{OR}=2.4,95 \%$ CI: 1.1 to 5.1$)$. Helzlsouer $\mathrm{K} \mathrm{J}$ et al. [56] considered that genetic variability in members of the GST gene family might be associated with an increased susceptibility to breast cancer $(\mathrm{OR}=3.77,95 \% \mathrm{CI}$ : 1.10 to 12.88$)$. Compared to the control group value of $41.8 \%$, Zhong $\mathrm{S}$ et al. [57] found a significant excess of $56.1 \%$ GSTM1 gene null individuals in colorectal cancer group. Our meta-analysis results demonstrate that there is an association between GST genetic polymorphisms and susceptibility to HCG in the Chinese population. Thus, further epidemiological and molecular biological studies are necessary to clarify the role of GST genetic polymorphisms in HCG and other carcinomas.

Nevertheless, there were several limitations to this metaanalysis. (1) Observational studies were susceptible to various biases such as selection bias. Due to some studies without clear explanation for the pathologic diagnostic results of all/part subjects (Table 1), therefore, some selection bias might be unavoidable. (2) In some studies, participants in control groups stemmed from hospital-based population might not fully represent the population-based controls, which could distort the results (Table 1). (3) The conclusions draw from subgroup analysis might be limited due to a low statistic power from the small sample size. (4) Each study had its own inclusive criteria. For example, some studies selected from $\mathrm{HbsAg}$ positive population, while others selected the common people or healthy population. Due to these reasons, some bias might bring influence on the results. (5) Not only genetic polymorphisms but other factors such as alcohol consumption, AFB1 status, and chronic infection of $\mathrm{HBV} / \mathrm{HCV}$ might also play vital roles in the development of HCC. Owning to the lack of sufficient data, gene-environment interactive functions were not evaluated in this meta-analysis, which might also have an influence on the precision of the conclusion.

In summary, our results suggest GST genetic polymorphisms are associated with the increased risk of HCC in the Chinese population. To further evaluate gene-to-gene and gene-toenvironment combined effects on GST genetic polymorphisms and HCC,both large scale multicenter epidemiological studies in total population and/or selected population with different environmental background are urgently needed. 

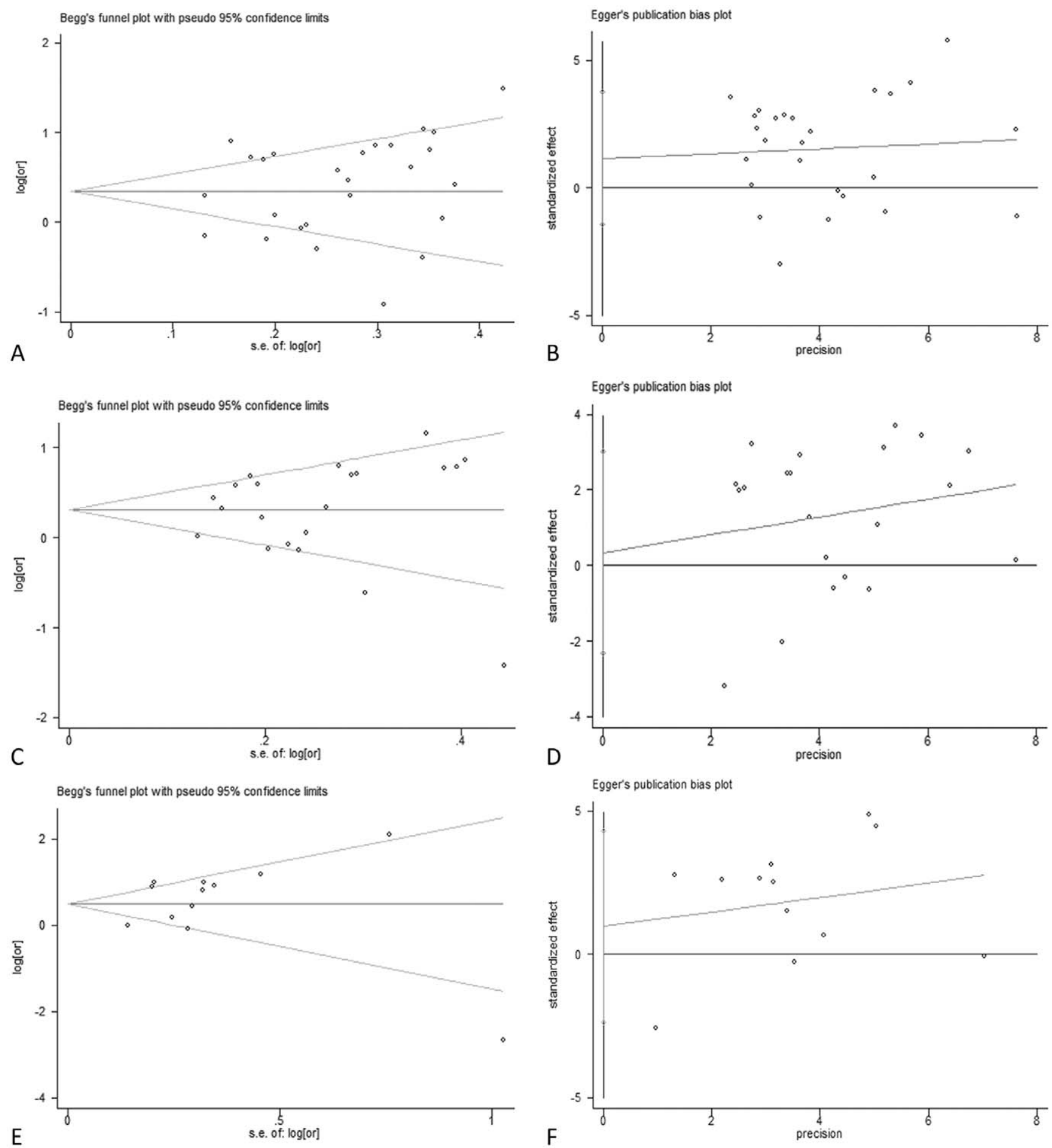

Figure 6. Beggar's test and Egger's test of GST polymorphisms and HCC risk. Beggar's funnel plot is used to detect potential publication bias in which a symmetric funnel shape means no publication bias. Egger's linear regression test is used to quantify the potential presence of publication bias. Both Beggar's test and Egger's test show that no publication bias has been found from 26 inclusive studies about the association between GSTM1 polymorphisms and HCC risk (A and B), 21 inclusive studies about the association between GSTT1 polymorphisms and HCC risk (C and D), and 12 inclusive studies about the association between dual-null genotype of GSTM1-GSTT1 and HCC risk polymorphisms and HCC risk (E and F).

doi:10.1371/journal.pone.0057043.g006 


\section{Acknowledgments}

The excellent assistance of Linda Bowman, Dechuan Kong and Jian Chen in the preparation of this article is greatly appreciated. This work was partly supported by K.C. Wong Magna Fund in Ningbo University.

\section{References}

1. Cabibbo G, Maida M, Genco C, Antonucci M, Cammà C (2012) Causes of and Prevention Strategies for Hepatocellular Carcinoma; 2012. Elsevier. pp. $374-$ 383.

2. Aghemo A, Colombo M (2012) Hepatocellular carcinoma in chronic hepatitis C: from bench to bedside; Springer. pp. 1-10.

3. French SW, Lee J, Zhong J, Morgan TR, Buslon V, et al. (2012) Alcoholic liver disease-Hepatocellular carcinoma transformation. Journal of Gastrointestinal Oncology 3: 174 .

4. Jemal A, Siegel R, Ward E, Hao Y, Xu J, et al. (2009) Cancer statistics, 2009. CA: a cancer journal for clinicians 59: 225-249.

5. Jemal A, Center MM, DeSantis C, Ward EM (2010) Global patterns of cancer incidence and mortality rates and trends. Cancer Epidemiology Biomarkers \& Prevention 19: 1893-1907.

6. Annick Buendia M. Genetics of hepatocellular carcinoma; 2000. Elsevier. 185200.

7. Thorgeirsson SS, Grisham JW (2002) Molecular pathogenesis of human hepatocellular carcinoma. Nature genetics 31: 339-346.

8. Farazi PA, DePinho RA (2006) Hepatocellular carcinoma pathogenesis: from genes to environment. Nature Reviews Cancer 6: 674-687.

9. Wang B, Huang G, Wang D, Li A, Xu Z, et al. (2010) Null genotypes of GSTM1 and GSTT1 contribute to hepatocellular carcinoma risk: evidence from an updated meta-analysis. Journal of Hepatology 53: 508-518.

10. Yu L, Wang CY, Xi B, Sun L, Wang RQ, et al. (2011) GST polymorphisms are associated with hepatocellular carcinoma risk in Chinese population. World Journal of Gastroenterology: WJG 17: 3248.

11. Chen J, Ma L, Peng NF, Wang SJ, Li LQ (2012) A meta-analysis of the relationship between glutathione S-transferases gene polymorphism and hepatocellular carcinoma in Asian population. Molecular Biology Reports: 1-11.

12. Beasley RP, Lin CC, Hwang LY, Chien CS (1981) Hepatocellular carcinoma and hepatitis B virus. The Lancet 318: 1129-1133.

13. McGlynn KA, Rosvold EA, Lustbader ED, Hu Y, Clapper ML, et al. (1995) Susceptibility to hepatocellular carcinoma is associated with genetic variation in the enzymatic detoxification of aflatoxin B1. Proceedings of the National Academy of Sciences 92: 2384-2387.

14. Udomsinprasert R, Pongjaroenkit S, Wongsantichon J, Oakley AJ, Prapanthadara L, et al. (2005) Identification, characterization and structure of a new Delta class glutathione transferase isoenzyme. Biochemical Journal 388: 763.

15. Atkinson HJ, Babbitt PC (2009) Glutathione transferases are structural and functional outliers in the thioredoxin fold. Biochemistry 48: 11108-11116.

16. Hayes JD, Flanagan JU, Jowsey IR (2005) Glutathione transferases. Annu Rev Pharmacol Toxicol 45: 51-88.

17. Strange RC, Spiteri MA, Ramachandran S, Fryer AA (2001) Glutathione-Stransferase family of enzymes. Mutation Research/Fundamental and Molecular Mechanisms of Mutagenesis 482: 21-26.

18. Higgins J, Thompson SG (2002) Quantifying heterogeneity in a meta-analysis. Statistics in Medicine 21: 1539-1558.

19. Huedo-Medina TB, Sánchez-Meca J, Marín-Martínez F, Botella J (2006) Assessing heterogeneity in meta-analysis: $\mathrm{Q}$ statistic or $\mathrm{I}^{2}$ index? Psychological methods 11: 193.

20. Hedges LV, Vevea JL (1998) Fixed-and random-effects models in meta-analysis. Psychological methods 3: 486

21. Begg CB, Mazumdar M (1994) Operating characteristics of a rank correlation test for publication bias. Biometrics: 1088-1101.

22. Egger M, Smith GD, Schneider M, Minder C (1997) Bias in meta-analysis detected by a simple, graphical test. BMJ 315: 629-634

23. Higgins J, Thompson SG, Deeks JJ, Altman DG (2003) Measuring inconsistency in meta-analyses. BMJ 327: 557-560.

24. Hsieh LL, Huang RC, Yu MW, Chen CJ, Liaw YF (1996) L-myc, GST Ml genetic polymorphism and hepatocellular carcinoma risk among chronic hepatitis B carriers. Cancer Letters 103: 171-176.

25. Bian JC, Wang JB, Wu Y (1996) Relationship between GSTM1 NULL genotype and genetic susceptibility to primary hepatocellular carcinoma. Chinese Journal of Medical Genetics 13: 353-353.

26. Hu Y, Sheng FM (1997) Association between GSTM1 gene polymorphism of primary hepatocellular carcinoma and mutation of p53 codon 249. Chinese Journal of Medical Genetics 14: 76-78.

27. Dong CH, Yu SC, Chen GC, Zhao DM, Fu YP. (1997) Polymorphisms of GSTT1 and M1 Genotypes and Their Effects on Elevated Aflatoxin Exposure and Increased Risk of Hepatocellular Carcinoma. Zhong Liu Fang Zhi Yan Jiu 24: $327-329$.

28. Dong CH, Yu SZ, Chen GC, Zhao DM, Hu Y (1998) Association of polymorphisms of glutathione S-transferase M1 and T1 genotypes with elevated aflatoxin and increased risk of primary liver cancer. World Chinese Journal of Digestology 6: 463-466.

\section{Author Contributions}

Proof read the manuscript: KL JSZ. Conceived and designed the experiments: JSZ KL LZ. Performed the experiments: KL XLL LLG. Analyzed the data: KL HBS RM BBZ. Contributed reagents/materials/ analysis tools: KL JSZ XLL. Wrote the paper: KL JSZ XLL.

29. Yu MW, Chiu YH, Chiang YC, Chen CH, Lee TH, et al. (1999) Plasma carotenoids, glutathione S-transferase M1 and T1 genetic polymorphisms, and risk of hepatocellular carcinoma: Independent and interactive effects. American Journal of Epidemiology 149: 621-629.

30. Bian JC, Shen FM, Shen L, Wang TR, Wang XH, et al. (2000) Susceptibility to hepatocellular carcinoma associated with null genotypes of GSTM1 and GSTT1. World Journal of Gastroenterology 6: 228-230.

31. Ma Y, Deng ZL, Wei YP (2001) Study of the deletion mutation of glutathione S transferase M1 gene and its role in susceptibility to hepatocellular carcinoma. Chinese Journal of Cancer Research 13: 176-178.

32. Wu HL, Cheng ML, Zhang RI (2000) Relationship Between GSTM1 Gene Polymorphism and Genetic Susceptibility to Primary Hepatocellular Carcinoma. The Practical Journal of Cancer 15: 463-465.

33. Zhu WC, Cheng Q Luo CL, Chu XW, Wu M (2001) Relationship Study Between Gene Polymorphism of CYP1A1,GSTM1 and Genetic Susceptibility of Primary Hepatocellar Carcinoma. China J Cancer Prev Treat 8: 572-574.

34. Sun CA, Wang LY, Chen CJ, Lu SN, You SL, et al. (2001) Genetic polymorphisms of glutathione S-transferases M1 and T1 associated with susceptibility to aflatoxin-related hepatocarcinogenesis among chronic hepatitis B carriers: A nested case-control study in Taiwan. Carcinogenesis 22: 12891294

35. Liu CZ, Bian JC (2002) Genetic Polymorphism of Glutathione S-transferase M 1,T1,P1on Susceptibility Hepatocellular Carcinoma. China Public Health 18: 935-936.

36. Liu ZG, Wei YP, Ma Y, ZL D (2003) Population with GSTT1 gene deletion and the relationship to hepatocellular carcinoma from guangxi. Journal of Guangxi Medical University 2: 002.

37. Yu MW, Yang SY, Pan IJ, Lin CL, Liu CJ, et al. (2003) Polymorphisms in XRCC1 and glutathione S-transferase genes and hepatitis B-related hepatocellular carcinoma. Journal of the National Cancer Institute 95: 1485-1488.

38. McGlynn KA, Hunter K, LeVoyer T, Roush J, Wise P, et al. (2003) Susceptibility to aflatoxin B1-related primary hepatocellular carcinoma in mice and humans. Cancer Research 63: 4594-4601.

39. Li SP, Wu JZ, Ding JH, Gao CM, Cao HX, et al. (2004) Impact of Genetic Polymorphism of Glutathione S-transferase T1,M1 on the Risk of Primary Hepatocellular Carcinoma in Alcohol Drinkers. The Practical Journal of Cancer 19: 229-232.

40. He SJ, Tan JR, Gu YY, Zhong WG, Su SG (2004) Relationship between Polymorphisms of Phase II Metabolic Genes and the Susceptibility to Hepatocellular Carcinoma in Guangxi. The Practical Journal of Cancer 19: $460-462$.

41. Guo HY, Bian JC, Jiang F, Wang QM, Zhang ZM, et al. (2005) The null genotypes of GSTM1 and GSTT1 and the genetic susceptibility of primary liver cancer in Luoyang,China. Tumor Jan 25: 58-61.

42. Ma DL, Chen YX, Li Y, Zhao HT, Xie XM, et al. (2005) Glutathione-Stransferase $\mathrm{M} 1$ and $\mathrm{T} 1$ polymorphisms and susceptibility to liver cancer in hepatitis B surface antigen positive population. Medical Journal of the Chinese People's Armed Police 27: 656-657.

43. Long XD, Ma Y, Wei YP, Deng ZL (2005) Study on the detoxication gene gstM1-gstT1-null and susceptibility to aflatoxin B1 related hepatocellular carcinoma in Guangxi. Chinese Journal of Epidemiology 26: 777-781.

44. Deng ZL, Wei YP, Ma Y (2005) Polymorphism of glutathione S-transferase mu 1 and theta 1 genes and hepatocellular carcinoma in southern Guangxi, China. World Journal of Gastroenterology 11: 272-274.

45. Long XD, Ma Y, Wei YP, Deng ZL (2006) The polymorphisms of GSTM1, GSTT1, HYL1*2, and XRCC1, and aflatoxin B1-related hepatocellular carcinoma in Guangxi population, China. Hepatology Research 36: 48-55.

46. Yang ZG, Xie YA, Kuang ZP, Luo XL, Zhang WM, et al. (2009) Relationship between genetic polymorphisms of glutathione-s-transferase M1,T1 genes and susceptibility to hepatocellular carcinoma in population of Fusui District of Guangxi Zhuang Autonomous Region. Chinese Journal of Cancer Prevention and Treatment 16: 970-973.

47. Kao CC, Chen MUK, Kuo WUH, Chen TY, Su SC, et al. (2010) Influence of glutathione-S-transferase theta (GSTT1) and mu (GSTM1) gene polymorphisms on the susceptibility of hepatocellular carcinoma in Taiwan. Journal of Surgical Oncology 102: 301-307.

48. Wei Y, Long X, Liu Z, Ma Y, Deng Z (2012) Genetic polymorphism of glutathione-S-transferase $\mathrm{M} 1$ and $\mathrm{T} 1 \mathrm{in}$ associated with carcinogenesis of hepatocellular carcinoma and nasopharyngeal carcinoma. Chinese-German Journal of Clinical Oncology 11: 138-141.

49. Tang YT, Li XP, Liu TQ Yang JR, Luo JQ et al. (2012) A study of genetic polymorphisms of Glutathione S-transferase in patients with hepatocellular carcinoma. Chin J Lab Diagn 16. 
50. Li CG, Zhao ZM, Hu MG, et al. (2012) Predictive Role of Glutathione-Stransferase Gene Polymorphisms in Risk and Prognosis of Hepatocellular Carcinoma. Asian Pacific Journal of Cancer Prevention 13: 3247-3252.

51. Chen CC, Yang SY, Liu CJ, Lin CL, Liaw YF, et al. (2005) Association of cytokine and DNA repair gene polymorphisms with hepatitis B-related hepatocellular carcinoma. International Journal of Epidemiology 34: 13101318.

52. Zhang YC, Deng CS, Zhu YQ (2005) Study on genetic polymorphisms of xenobiotica metabolizing enzymes in hepatitis B virus- associated hepatic disease. Wenzhou Yi Xue Yuan Xue Bao 35: 464- 467.

53. Zhu MH, Chen XH, Zhou LF (2005) Association of genetic polymorphisms in glutathione S-transferases M1 with hepatitis beta-related hepatocellular carcinoma. Journal of Zhejiang University (Medical Sciences) 34: 126-130.

54. Katoh T, Nagata N, Kuroda Y, Itoh H, Kawahara A, et al. (1996) Glutathione S-transferase M1 (GSTM1) and T1 (GSTT1) genetic polymorphism and susceptibility to gastric and colorectal adenocarcinoma. Carcinogenesis 17: 1855-1859.

55. Wang J, Deng Y, Cheng J, Ding J, Tokudome S (2003) GST genetic polymorphisms and lung adenocarcinoma susceptibility in a Chinese population. Cancer Letters 201: 185.

56. Helzlsouer KJ, Huang HY, Hoffman S, Alberg AJ, Comstock GW, et al. (1998) Association between glutathione S-transferase M1, P1, and T1 genetic polymorphisms and development of breast cancer. Journal of the National Cancer Institute 90: 512-518.

57. Zhong S, Wyllie A, Barnes D, Wolf C, Spurr N (1993) Relationship between the GSTM1 genetic polymorphism and susceptibility to bladder, breast and colon cancer. Carcinogenesis 14: 1821-1824.

58. Deng CH, Zi XL (1997) Relationship between Deletion of Slutathion Strausferase Gene and Susceptibility to Primary Hepatocellular Carcinoma. Chinese Journal of Public Health 16: 141-142.

59. Yu MW, Gladek-Yarborough A, Chiamprasert S, Santella RM, Liaw YF, et al. (1995) Cytochrome P450 2E1 and glutathione S-transferase M1 polymorphisms and susceptibility to hepatocellular carcinoma. Gastroenterology 109: 12661273 .
60. Chen CJ, Yu MW, Liaw YF, Wang LW, Chiamprasert S, et al. (1996) Chronic hepatitis B carriers with null genotypes of glutathione S-transferase M1 and T1 polymorphisms who are exposed to aflatoxin are at increased risk of hepatocellular carcinoma. American Journal of Human Genetics 59: 128.

61. Yu MW, Lien JP, Chiu YH, Santella RM, Liaw YF, et al. (1997) Effect of aflatoxin metabolism and DNA adduct formation on hepatocellular carcinoma among chronic hepatitis B carriers in Taiwan. Journal of Hepatology 27: 320 330 .

62. Bian J, Shen F, Wang J, Chen G, Zhang B, et al. (1999) The mutation of deletion for glutathione S-transferase M1 gene in the tissue of hepatocellular carcinoma. Chinese Journal of Medical Genetics 16: 171-173.

63. Sun C, Wu D, Wang L, Chen C, You S, et al. (2002) Determinants of formation of aflatoxin-albumin adducts: a seven-township study in Taiwan. British Journal of Cancer 87: 966-970.

64. He S (2005) the analysis of GSTM1,GSTT1 gene polymorphism in HCC. Joural of Guangxi Medical University 22: 875-877.

65. He SJ, Gu YH, M ZH (2007) Effect of interaction between smoking, alcohol drinking and polymorphisms of phase II metabolic genes on the susceptibility of hepatocellular carcinoma. Basic Medical Sciences and Clinics 27: 666-669.

66. He SJ, Gu YH, M ZH (2008) The association between GSTM1 gene polymorphism and wine,tobacco habit and susceptibility in primary liver cancer. Journal of Guangxi Medical Unversity 25.

67. Long X, Ma Y, Wei Y, Deng ZL (2005) A study about the association of detoxication gene GSTM1 polymorphism and the susceptibility to aflatoxin B1related hepatocellular carcinoma. Chinese Journal of Hepatology 13: 668.

68. Deng Z, Wei Y, Ma Y (2001) Glutathione-S-transferase M1 genotype in patients with hepatocellular carcinoma. Chinese Journal of Oncology 23: 477-479.

69. Wei YP, Ma Y, Deng ZL (2004) Genetic polymorphisms of Glutathione Stransferase $\mathrm{M} 1$ and $\mathrm{T} 1$ and the risk of hepatocellular carcinoma. Tumor 23: $464-466$.

70. Wei YP, Long XD, Liu CZ, Ma Y, Deng ZL (2010) Genetic polymorphism of glutathione-S-transferase $\mathrm{M} 1$ and $\mathrm{T} 1$ in associated with carcinogenesis of hepatocellular carcinoma and nasopharyngeal carcinoma. Cancer Research On Prevention And Treatment 37: 1162-1165. 